\title{
Hedonic Inertia and Underground happiness
}

D’Acci L. (2012). Hedonic inertia and underground happiness, Social Indicators Research DOI : $10.1007 / \mathrm{s} 11205-012-0137-2$

The final publication is available at http://link.springer.com

http://link.springer.com/article/10.1007/s11205-012-0137-2?LI=true\#page-1

\begin{abstract}
The happiness of people is formulized by an Underground Hedonic Theory taking into account several levels. A formal way to think of and measure Underground happiness passes through the idea of Hedonic Inertia. This is the "residual happiness", the "substratum of feeling" given by our experiences lived in each different moment of our days. The concept of happiness as the temporal integral of momentary utility is focused, pointing out the role that one or more events in our day can influence our mood throughout the entire day. We also refer to the underground happiness coming from our general situation (love, career, money, national politics, etc.), and from the underground scenario of our daily activities (urban beauty, noisiness, comfort, etc.). Finally we summarize the logical steps to design a certain Profile of Hedonic Response for a certain person, or personality typology, as a set of particular Curves of Hedonic Ponderation. This is also explained in a mathematical way by an "equation of happiness".
\end{abstract}

Keywords Subjective Well-Being, momentary happiness, hedonic profile, Underground Hedonic Theory, happiness equation.

\section{Introduction}

A 1917 article of Myerson proposing a discipline of "empathics" as the study of "the wellbeing of the normal", probably marked the origin of a science of wellbeing (Angner, 2011).

Measures of happiness appeared in applied branches of psychology, medicine and sociology to understand the causes of happiness; they emerged in marital studies (Davis K.B.) in 1929, in educational psychology (Watson G.) in 1930, and in personality psychology (Allport ${ }^{1}$ in 1937 and Murray in 1938). After these initial developments, a certain number of studies to measuring subjective wellbeing emerged, such as Hart (1940) with his "chart of happiness"; Goldings (1954) and his hypothesis of projected happiness; Gurin's surveys (1960); Neugarten (1961) and his life-satisfaction indexes; Campbell's indexes of general affect and well-being (1976); the "Delighted-Terrible Scale" (D-T) of Andrews and Withey (1976); multiple-item approaches as the "Satisfaction With Life Scale" of Diener and Pavot (1993); etcetera till the Kahneman studies that gave him the Nobel Prize (Kahneman 2010).

\section{Temporal integral of momentary utility methods}

Psychological studies ${ }^{2}$ show numerous types of problems that occur when people try to judge their happiness; Kahneman proposed a method of evaluating the global happiness of a person by creating a reconstruction of the previous day: Day Reconstruction Method (DRM). The respondent rates each episode in terms of its positive or negative effect (momentary utility), and says how long each episode was. Therefore, the global happiness is the temporal integral of momentary utility (Kahneman 2006, 2003).

The idea of the total day happiness as temporal integral of momentary utility comes from the utilitarian Jeremy Bentham (1789), Francis Ysidro Edgeworth (1881), and Alfred Marshall

\footnotetext{
${ }^{1}$ Albort $(1935,1937)$.

${ }^{2}$ Kahneman $(2006,2004,1994)$.
} 
(1890). Kahneman called this concept experienced utility and it is pretty similar to the process benefits $^{3}$ of Juster, Courant and Dow (1985).

\section{The concept of Hedonic Inertia}

Imagine to ask person $x$ to describe his activities during his typical day. After this, we ask him how happy he usually is right when he is doing his typical activity, using a scale of happiness from -5 to 5 , where -5 is the maximum level of unhappiness, 0 is a neutral feeling, and +5 is the maximum level of happiness. Then, we ask him how long these activities usually take. For example, we can receive the reply illustrated in Fig. 1.

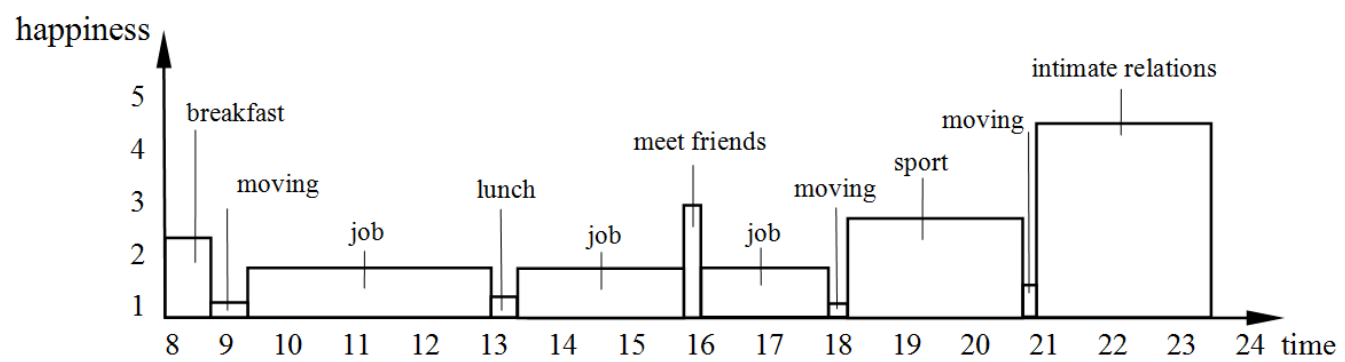

Fig. 1. Example of happiness during a typical day of person $x$

Thus, asking that question, person $x$ would probably reply thinking of his happiness just during each specific activity. For example, when he says that usually, during his typical day, he feels happy " 3 " meeting his closest friends, and feels happy " 2 " when he is working at the office, he is evaluating his happiness on those specific actions. However, one event in our day, independently from its duration, can influence our mood throughout the entire day. For instance, if we know that in the evening we will have a very nice activity (or if we have already had it), that gives us a great joy and we will feel its positive influence all day long. In the same way, one or two very happy days (for example a nice week-end) could make us feel a bit happier all week long.

We could call this residual underground happiness Hedonic Inertia $(H I)$.

For the purpose of estimating the global happiness in a typical day, we should also consider the effect of the Hedonic Inertia, because the 2 hours in a day spent wonderfully (or badly) can influence the rest of our day. In this way, the momentary happiness spreads throughout the day.

For example, we can think of these two extremely simple situations: person A says to be happy " 3 " all day long when he usually does activity $j_{1}$; person B says to be usually happy " 2 " doing activity $j_{1}$, and " 5 " doing $j_{2}$. Imagine to simulate a virtual day in which A spends 15 hours doing $j_{1}$, and $\mathrm{B} 12$ hours doing $j_{1}$, and 3 hours doing $j_{2}$. When we measure the total happiness $(\mathrm{H})$ as the sum of the momentary happiness during that day (the temporal integral of momentary happiness), we obtain that person $\mathrm{A}$ is happy $\mathrm{HA}=3 * 15=45$, and person $\mathrm{B}$ is happy $\mathrm{HB}=2 * 12+5 * 3=39$, that means $\mathrm{A}$ is happier than $\mathrm{B}$.
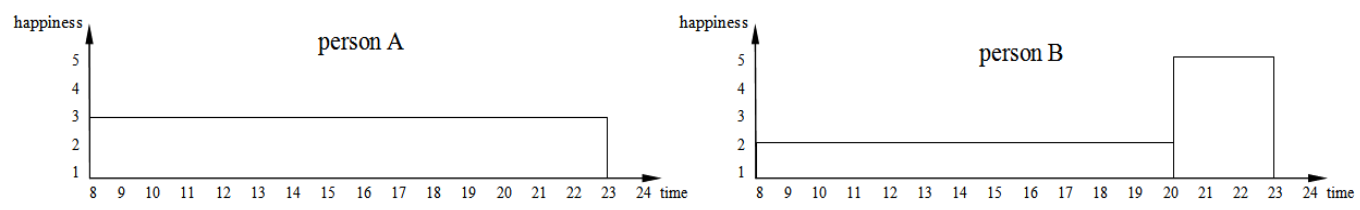

\footnotetext{
3 "direct subjective consequences from engaging in some activities to the exclusion of others... For instance, how much an individual likes or dislikes the activity 'painting one's house', in conjunction with the amount of time one spends in painting the house, is as important determinant of well-being independent of how satisfied one feels about having a freshly painted house" (Juster, Courant, Dow, 1985).
} 
Fig. 2. Example of happiness during a day of persons A and B

If we consider the Hedonic Inertia effect too, it could result that $\mathrm{B}$ is happier than A. Actually A is pretty happy (" 3 ") all day, but B, although he is a little bit unhappier ("2") than A almost all day, he is very happy ("5") in the night and this happiness spreads throughout the entire day (Hedonic Inertia hi), then his own general mood will be better all day. On the contrary, A cannot feel happier than " 3 " during the day.

There are also two other kinds of underground happiness, that we can call $u$ when it is related to our general condition such us money, health, love, political-social conditions, etc., and $U s$ when it is related to the underground scenario in which the activities take place (silence, company, aesthetics, etc.).

Calling $h^{\prime}$ the happiness strictly given from the activity we will have: $h=h^{\prime}+U_{s}$, and we measure the Global Happiness of an entire day $(G H)$, as a sum of:

- $\quad$ the sum $(\mathrm{H})$ of each happiness $(h)$ from each activity $(j)$;

- the sum (HI) of each hedonic inertia $(h i)$ of each activity $(j)$ during the day;

- $\quad$ the underground happiness $(u)$ :

$$
\begin{gathered}
G H=H+H I+u \\
H=\int_{t_{w}}^{t_{s}}\left(h \not t=\sum_{j} h_{j} \cdot t_{j}\right. \\
H=\int_{t_{w i}}^{t_{s}} h \quad \phi=\sum_{j} h_{j} \cdot T \\
h_{j}=\left(\frac{\left|h_{j}\right|}{|\mathrm{m} h|)}\right)^{n} \cdot \frac{h_{j}}{\left|h_{j}\right|} \cdot f\left(t_{j}\right) \delta \\
i^{\mathrm{a}} \\
\mathrm{x}
\end{gathered}
$$

In which a person says to feel happy $h$ during activity $j$ which lasted the time $t_{j}$; $\max h$ is the maximum value of the scale used (in our example it is 5 ). $\mathrm{T}_{\mathrm{w}}$ is the hour when the person wakes up, $\mathrm{T}_{\mathrm{S}}$ is when he goes to sleep, $\mathrm{T}$ is $\mathrm{T}_{\mathrm{S}^{-}} \mathrm{T}_{\mathrm{W}}$.

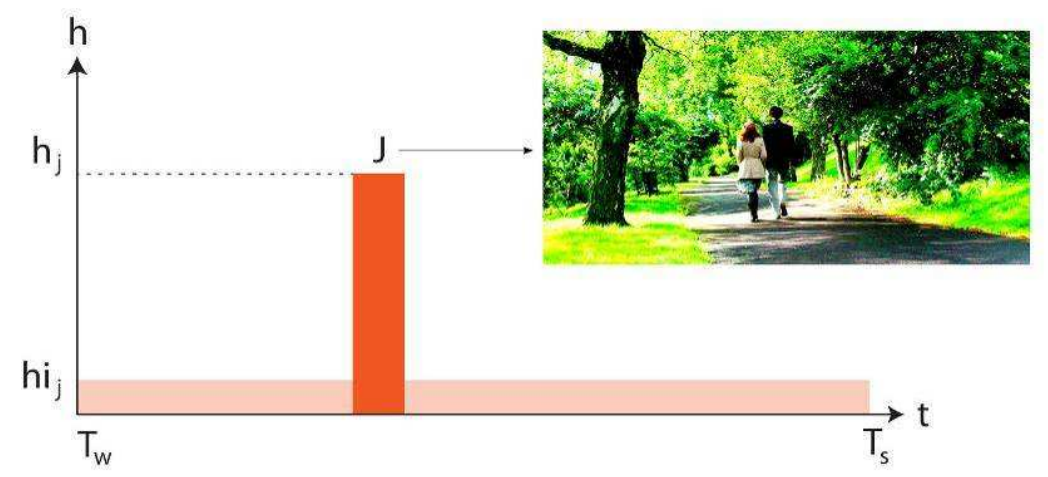

Fig. 3. Example of the Hedonic Inertia of an activity $j$

In the example of Fig. 3, if we ask the person to say how happy he is in that moment, he reply (we will call it " $w$ " in the next paragraph") will include: the happiness $(h$ '), connected to 
the activity $j$ "walking"; the one $\left(U_{S}\right)$ connected to the fact that he is walking in a nice park and with his partner (underground scenario); the one (HI), connected to the happiness received from the other activities of the day; and the one $(u)$ connected to his underground situation (career satisfaction, economic situation, health, family...).

We consider the case to estimate the global happiness of a day as a global evaluation, a comprehensive judgment of the happiness of the entire day, a post-evaluation, not a pre, or a in itinere evaluation; not a sum of the happiness of the day, or as the average happiness of the day (mathematical mean of the algebraic sum of momentary happiness during the day). If it was a measurement of the sum of the happiness during the day, it would be necessary to consider the fact that the hedonic inertia of activity $j$ has an effect before activity $j$ only if one already knows that he will have that activity later in the day.

In this paper we do not want to think about an algebraic sum, but about a psychological sum of experienced happiness.

The final number $(\mathrm{GH})$ of the global happiness of the day is meaningless. What could be useful is the relative difference among diverse typical days for the same person, or similar typology of person. However, even in this case, it is questionable that a day with 15 hours at $h=0$, is equivalent with a day with 13 hours at $h=0,1$ hour at $h=-5$, and 1 hour at $h=+5$ : even if it can result algebraically equivalent, it does not mean that it is psychologically equivalent too.

This is not a given formula, but an Open Formula. It should be adapted by following the empirical and theoretical researches, and the typology of people ${ }^{4}$. This can be done thanks to the parameters $n, \delta$ and to the function $f\left(t_{j}\right)$.

The parameter $n$ allows to qualitatively change the graphical shape of the function (that means the $h i$ effect of each value of $h$ ); while $\delta$ allows to quantitatively change the function by amplifying all the values of $h i$, that means deciding what importance to give $h i$ on the overall calculation of the day's happiness.

The higher value of $n$ we choose, the higher the influence of the highest happiness/unhappiness experienced during the day will be, not in absolute terms, but in relative terms, in comparison with the lower happiness/unhappiness levels during the day. In this way we can chose how much the happiest and unhappiest experience have the greatest influence. By following common sense, it seems realistic to think that it is the highest level (or higher levels) of happiness/unhappiness felt during the day that has more impact on the overall day's happiness. However this does not mean that only the happiest activity/ies of the day influence the overall day's happiness, in fact, as the equation and the next figures show, each activity of the day influence the global hedonic inertia.

The higher $\delta$ is, the higher the Hedonic Inertia effect is.

For example a more passionate, sensitive character could be associated with a higher value of $\delta$, because he is supposed to be more perceptive to the effect of strong feelings felt during some times of the day, and he will keep that feeling (happiness or unhappiness) during all the other parts of the day more than a person who is dispassionate, cold, frigid, with a more rigid nature.

$f\left(t_{j}\right)$ allows to calibrate the influence that the time $\left(t_{j}\right)$ of the activity $j$ has on $h i$.

From the point of view of a global psychological sum evaluating the mood/happiness of the day, it is reasonable to think that the level of happiness felt $(h)$ is more important rather than how long it was experienced. It will not be so central, for this kind of judgment, if a great laugh with a friend has been carried out for 5 minutes, 10 minutes or half an hour. What one could keep in mind during the full day, or what he could "spread" in his global judgment of the day's happiness, is the memory of the intensity rather than the duration. However, also the time period of the activity that gave a certain happiness level has its influence: the $h i$ of an activity, (e.g. work in a very unpleasant/pleasant place), that lasts for 1 hour, will be different from the $h i$ of the same activity but which lasts for 8 hours.

As $f\left(t_{j}\right)$ we propose an easy equation like:

$$
1+\frac{t_{j}-1}{k} \quad t^{\prime} \quad t_{j} \leq 1 \rightarrow t_{j}=1
$$

\footnotetext{
${ }^{4}$ We are proposing this formula just to coarsely give a numerical and graphical example of the concept of hedonic inertia, but we are certain that it can have some mistakes and that it has missing parts.
} 
Where each $t_{j}$ from 0 to 1 hour is considered $1 \mathrm{~h}$. This following the above written hypothesis that a happy/unhappy event (like a great laugh with a friend, or a bad phone call from the office), will have its effect on the entire day's mood quite independently from the fact that it lasted for 5 minutes, 10 minutes, 30 minutes, etc. What could have more impression during the day, could be the intensity of the feeling rather than its duration.

However we should separate the effect on our global mood during the day of an activityfeeling lasting 20 minutes from one lasting 6 hours. Also in this case we leave the formula opened thanks to parameter $k$ : if we prefer to follow the idea that, apart from the case of short events (from 0 to 1 hour), the intensity $\left(h_{j}\right)$ and the duration $\left(t_{j}\right)$ are equally important, we will choose $k=1$; if we do not want to give any importance to $t_{j}$, even since the first minutes, $f\left(t_{j}\right)$ will be just " 1 " (or we can choose $k=1000$ for example); if we want to give the same importance of the duration also for short events, $f\left(t_{j}\right)$ will just be $t_{j}$; the higher $k$, the lower the influence of the duration of the event will be (Fig. 4). We can also choose different functions to ponder the effect of $t_{j}$, using for example some logistic function shapes (Fig. 5). In any case, it is reasonable to assume that, independently from the duration, $f\left(t_{j}\right)$, and from the combination of $n$ and $\delta$ chosen, a certain $h i_{j}$ associated to its $h_{j}$, should not be higher than $h_{j}$ itself. However, an effect of some particular events $j$, such as a phone call saying that you won a job, or that you have a serious disease, or that your partner died, etc., will not just have an $h i$ effect, but, especially, an $u$ effect, because such kinds of events will become immediately part of the underground happiness $(u)$ too.

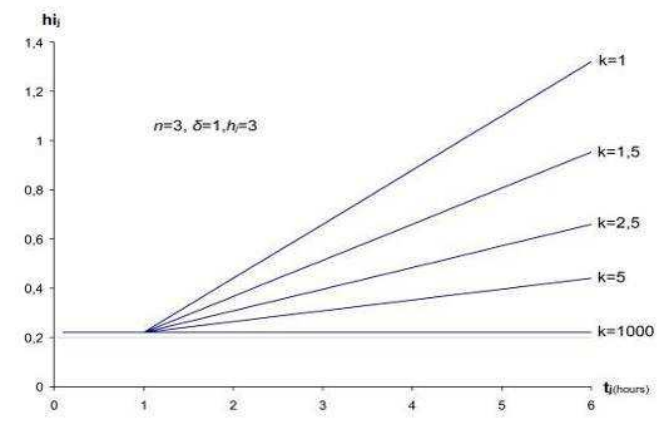

Fig. 4. $f\left(t_{j}\right)$ effect changing parameter $k$

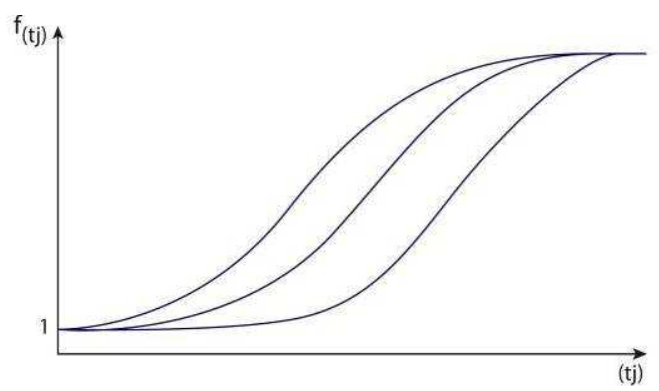

Fig. 5. Example of logistic shapes for $f\left(t_{j}\right)$

As the reader will argue, this formalization to quantify the global happiness of a day with a number, is without meaning if we try to use it for comparing different people (or the same person but in a different life period): each one can have different reactions and different feelings for the same experience. A pessimistic, depressive nature could amplify the negative feelings, while an optimistic, positive nature could give more importance to the positive feelings. Also, a person with a different background, culture, memories, education, genetic factors, etc., will enjoy in a different way watching a sunset, or living in a busy megacity, reading a book, walking in nature, sitting by a fireplace, doing sport, looking at the snow from the window, etcetera.

This formalization can be used for comparing different scenarios for a same person, or, by introducing a stochastic variable, for a "standard typology" of people.

Imagine a day with 0 level of happiness $(h=0)$ during the entire day, except for 1 hour in which $h$ is not 0 : the next figures show the different values of $h i$ when the level of $h$, experienced during 1 hour of time, changes between 1 and 5, and considering 15 hours as $\mathrm{T}$ (the "no sleeping time" $\left(\mathrm{T}_{\mathrm{s}}-\mathrm{T}_{\mathrm{w}}\right)$ ). The figure shows an example about how the hi change by 
modifying the parameters $n$ and $\delta$ : by varying $n$, we obtain the Shape Curves of hi (Fig. 6 ); by varying $\delta$, we obtain the Amplification Curves of hi (Fig. 7). Combining Shape Curves, Amplification Curves, and different symmetries with respect to the origin of the axes, we obtain the Ponderation Curves of hi. A single curve of the Ponderation Curves, is associated to a specific person, and we call it Profile of hi Perception (Fig. 14).

It is also thanks to theses curves, and to $f\left(t_{j}\right)$, that we can have a global psychological sum, rather than just an algebraic sum.

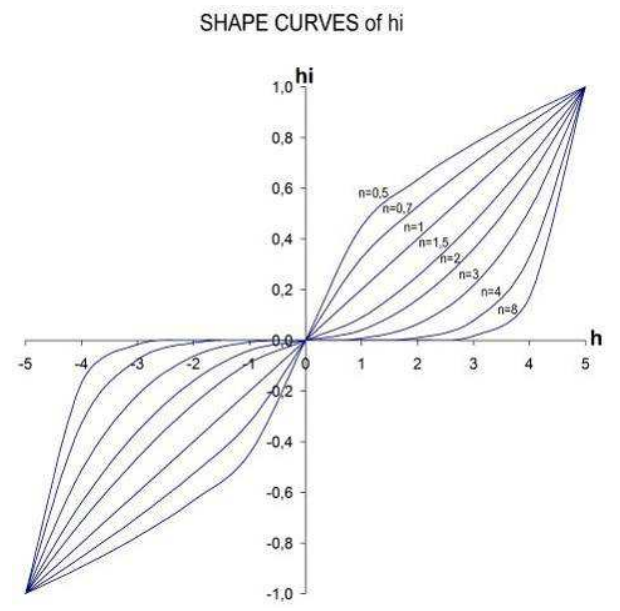

Fig. 6. Shape Curves: example of $h i$ changing the parameter $n$, with $\delta=1$

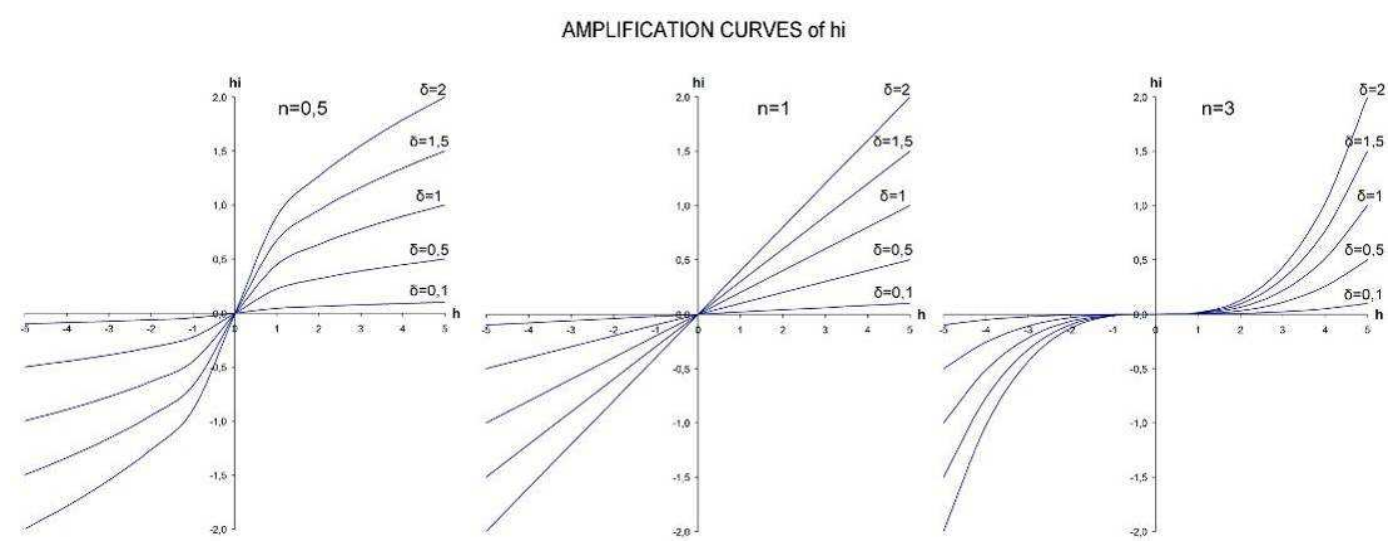

Fig. 7. Some examples of Amplification Curves of hi

Using equation (4), to calculate $h i$, we find that person B of the previous example is happier than person $\mathrm{A}$ : without considering $h i$, it results $\mathrm{A}=45$ and $\mathrm{B}=39$, but considering $h i$, it results $A=63$ and $B=68$ (Fig. 8).

\begin{tabular}{|c|c|c|c|c|c|c|c|c|c|c|}
\hline & \multicolumn{3}{|c|}{ INPUT } & \multicolumn{3}{|c|}{ PARAMETERS } & \multicolumn{4}{|c|}{ OUTPUT } \\
\hline & $\mathrm{h}$ & $\mathrm{t}$ & $\mathrm{T}$ & $n$ & $\delta$ & $k$ & hi & $\mathrm{H}$ & $\mathrm{HI}$ & $\mathrm{GH}$ \\
\hline A & 3 & 15 & 15 & 3 & 1 & 3 & 1,22 & 45,00 & 18,36 & 63,4 \\
\hline B & $\begin{array}{l}2 \\
5\end{array}$ & $\begin{array}{c}12 \\
3\end{array}$ & 15 & 3 & 1 & 3 & $\begin{array}{l}0,30 \\
1,67\end{array}$ & $\begin{array}{l}24,00 \\
15,00\end{array}$ & $\begin{array}{c}4,48 \\
25,00\end{array} \quad 29,48$ & 68,5 \\
\hline
\end{tabular}

Fig. 8 Comparison between $\mathrm{H}$ and $\mathrm{GH}$ (through hi) in two cases. 


\section{Conscious and unconscious Hedonic Inertia}

The Hedonic Inertia of an event $j$, is existent only when the effect of $j$ is in the mind. This happens when one is thinking about $j$, and we define this case as Conscious Hedonic Inertia, $h i_{c}$. During the day, a person can think about $j$ at different periods of time, and at different intensities. For example if $j$ is "during your lunch break visiting the person you are falling in love with", one can intensely think about this during his breakfast; after he might not think anymore about it during a couple of hours at the office because his mind will be fully busy; after he could go back to thinking about $j$, more or less intensely, during several other moments, and so forth (Fig. 9 on the right).

Independently from the fact that one directly thinks or not about $j$, the fact that he will have/had a wonderful meeting with the person with whom he is falling in love, is underground in his mind; he knows it, and even when he is busy at the office and he stops directly thinking about $j$, his underground mood is in part influenced from $j$, proportionally to the intensity of $j$. Using the word "unconscious" in a superficial sense, without troubling its real, profound psychological meaning, we could call Unconscious Hedonic Inertia, hi $i_{u}$ this underground feeling coming from $j$ also when one does not directly think about it (Fig. 9 on the left).
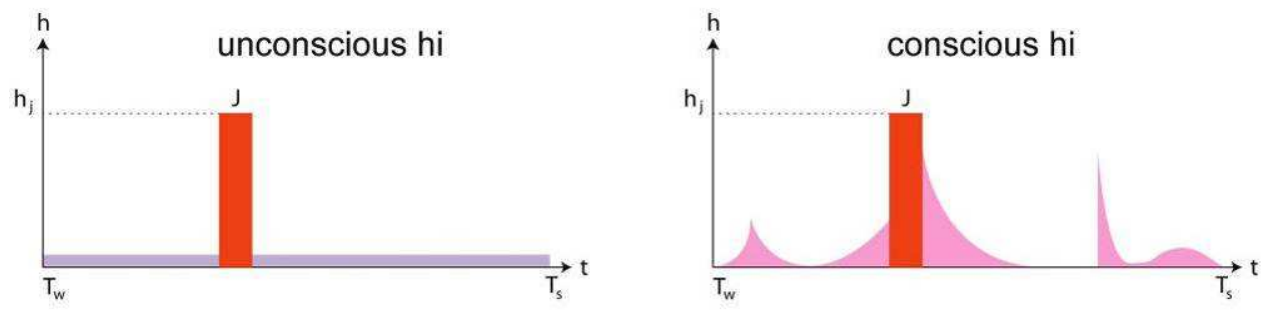

Fig. 9. Example of Conscious Hedonic Inertia and Unconscious Hedonic Inertia

The sum of the conscious and unconscious effect, gives $h i$. In this paper we generally consider the conscious hedonic inertia as uniformly spread throughout the day.

This separation between the conscious and unconscious effect, will not be evidenced for the underground happiness that we will discuss in the next paragraph, because it is realistic to think that one cannot "forget" that he is jobless, or single, or in love, or that in front of his room window there is a wonderful park rather than a polluted factory, or that his country is in a war. Even when he is not continuously directly thinking "I am jobless", he is permanently quite conscious of it, or, from another point of view, we can say that the unconscious component is so big in these cases, that it is in anyway predominant. We can just think how our general mood can constantly be up (or down), during a long period of time because of one of the reasons connected to the underground happiness factors (losing the job, falling in love, etc.), even if we do not constantly think about it every minute.

\section{The concept of Underground happiness}

Regarding the underground happiness $(u)$ briefly mentioned before, it is realistic to think that, when one is asked how happy he is in moments/events $(j)$ during a specific day, it is included in the replies. Then, each level of happiness, given from each activity during the day, is probably including (increasing or decreasing all of them a little bit) the average happiness underground coming from global conditions like money, love, health, job, politics, family ... Idem for $h i$.

We can define another kind of "underground happiness" that we call underground happiness from the scenario $(U s)$. It is that part our feeling, during normal activities of the day, connected with factors such as the aesthetical quality of the building where one lives and where one works, the pleasantness of the urban environment during a walk, the comfort of a bus/tram/car when commuting, the genius loci of a place, and so forth.

It is sensible to think that $U s$ is naturally included when one judges his level of satisfaction received $(h)$ from a certain activity $(j)$. For example, the feeling of a person during a walk $(h)$, does not depend just from the walk itself $\left(h^{\prime}\right)$, but also (or maybe mostly), from the underground scenario $(U s)$, such as the environmental quality, the company, the noise, the memories that the place gives to him, etcetera.

When $h i$ and $u$ are already, consciously or unconsciously, included in the reply, we can call $w$ the expressed level of happiness in each different activity $(j)$ of the day, and $h$ (as before) the 
level of happiness connected to each specific activity including $h^{\prime}$ and $U s$; so the equation becomes:

$$
\begin{aligned}
& G H=\int_{t_{w}}^{t_{s}} w d t=\sum_{j} w_{j} \\
& w_{j}=h_{j}+\sum_{j} h i_{j}+u
\end{aligned}
$$

We assumed that if one, during a certain moment of the day (activity $j$ ), is asked "How happy are you in this moment?", his reply $(w)$, is already including: the happiness $\left(h_{j}\right)$ from activity $j$; the sum of the hedonic inertia of all the activities of the day ${ }^{5}$, and the underground happiness (job/love/health/politics... situation); where $h_{j}$ includes $U s$.

Equally we assume that if one is asked "how happy are you usually during activity $j$ ?", his reply could just be connected to $h_{j}$ ' or $h_{j}$, depending from the specification of the question.

Here, we show just the concept of the hedonic inertia, but to quantify it correctly we should pass through specific empirical researches that should be able to separate each contribution.

It is rather evident that the mood during an activity is partially influenced from its adjacent activities. For example, the "happiness" expressed in a research of Kahneman (2004, 2004a), (he calls it: experienced utility) shows how the same activity can have a different score in relation with its closely adjacent activities. In fact, the activity "Morning commute" (transfer from home to work) has the average score (from 0 to 6) of 2.09, whereas the "Evening commute" (transfer from work to home) has 2.77.

The next figure shows some average experienced utility (or Net Affect) scores, concerning some episodes during the day, from the above-mentioned research (Kahneman 2004a) carried out on a sample of 909 employed women in Texas.

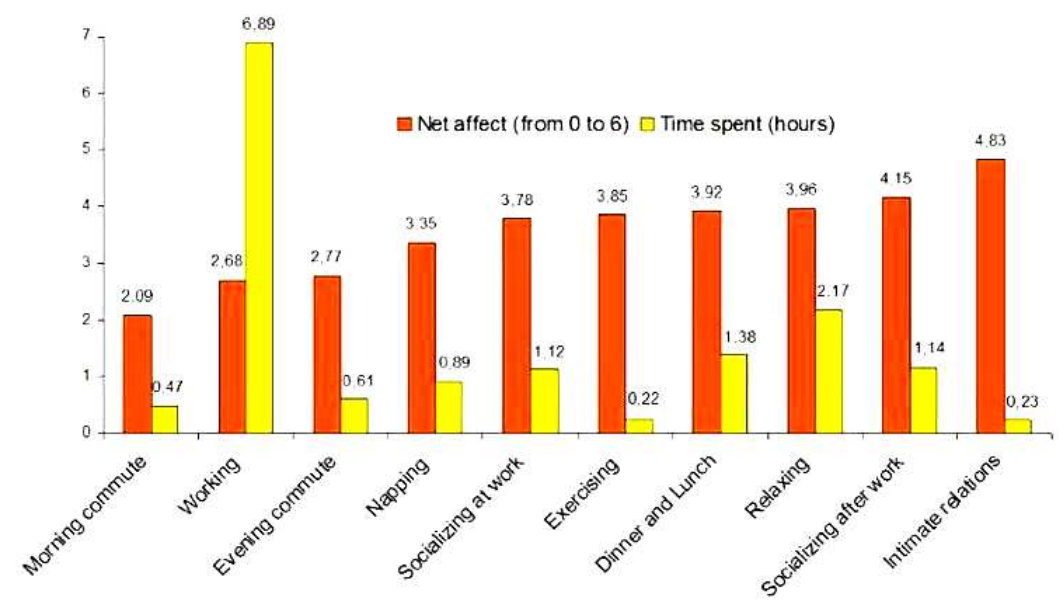

Fig. 10 "Happiness" (Net affect), and Time spent for some activities.

Source: graphic of data from Kahneman and others (2004a), in D’Acci (2010, 2012).

Looking at fig. 10, we see that the greatest experienced utility in a day is during the 0.23 hours (about 14 minutes) of intimate relations (sex). From the supposition that these 14 minutes probably improve the average mood a bit during the day, we present the following question: if, ceteris paribus, the interviewed did not have those 0.23 hours of "intimate relations", all his other scores, given to every other activity in his day, would decrease or would stay the same? If they decrease, it will mean that his previous scores had already included the Hedonic Inertia effect of those 14 minutes; otherwise we should introduce it in our evaluation. Then, isolating the whole contribution of $h i$, we could ask the same person to give his scores for each activity in two different times: one (a), when during his typical day there is a very pleasant activity, valuing $h=5$, during, e.g., 2 hours, and another (b), when during his

\footnotetext{
${ }^{5}$ The reader will notice that, in the case of unexpected activities of the day (when one does not know of them before they will happen), the sum of $w$ during the day will not give the global psychological sum, the comprehensive judgment of the happiness of the entire day as we previously explained.
} 
typical day (with all the same activities as before) we remove this very pleasant activity. If we do that for a sample of $n$ people, we could observe if ${ }^{6}$ and how much, in average, all the other scores given in each activity show a difference between the situations (a) and (b).

On the other hand, if between the situations (a) and (b) nothing changes during his daily activities, but in (b) the person is richer, or ill, or in love, or living in a less agreeable area or town, and so forth, we could observe how much the influence of $u$ is.

In another way, it is possible to isolate the effect of $u$ through the comparison among the average expressed happiness of people assembled in categories.

Research, carried out by Leu, Burri and Priester (1997) in Switzerland, on a sample of more than 6000 people, shows, by multiple regression, the correlation among several socioeconomic, demographic, institutional variables and the level of life satisfaction (using a scale from 1 to 10). The next figure shows the influence of some of these variables; in this histogram the length of the bar love indicates the difference between the average score of life satisfaction of people "married" and of people "separated and living alone", keeping constant all the other variables. Health indicates the same kind of comparison, but between people with "good health" and "bad health". While money is the comparison between people with "income SFr.5000 and more" and "income less than SFr.2000"; education is between people with "elevated education" and "base education".

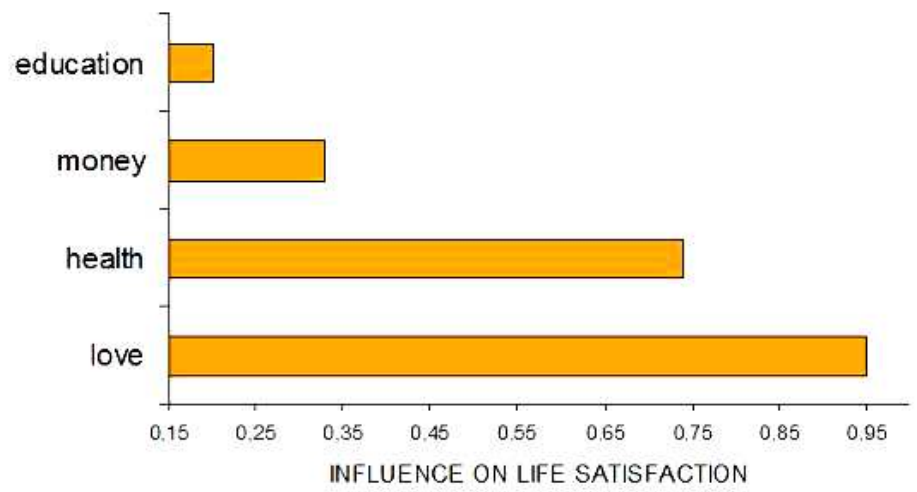

Fig. 11. Influence on life satisfaction.

Source: graphic from the data of Leu, Burri, Priester (1997), in D’Acci (2010, 2012).

\section{Hedonic Inertia and Underground happiness influence on Daily Happiness}

As we wrote, subjective wellbeing (experienced happiness, mood, satisfaction, etc.), is connected, ceteris paribus, to gender, education, age, culture, and so forth.

A same event ${ }^{7} j$ (walking, doing sport, etc.), can be felt as $h_{j}{ }^{\prime}=+5$ from a person, and as $h_{j}{ }^{\prime}=+2$ from another person. Calling $I j$ the "objective" "intensity" of an event (or, in some cases, more easily, "an event"), we can have different replies for a same Ij: Ponderation Curves of h' (Fig. 12).

It is dubious to be able to quantify in a scale of measurement the objective intensity of an event. However, in order to give the idea, we can think of the objectiveness to be in front of the classical half glass of water ("half" in this case would represent the "objective quantification of the intensity"), and seeing it (Ponderation Curves of $h$ '), half, almost full, or almost empty.

We can also think to have a group of people (with the same level of underground happiness $u$ and a relative ${ }^{8}$ similar type of day, that means a comparable $\mathrm{HI}$ ), sitting down on the same bench and watching the sunset (same "Ij"): some can feel ${ }^{9} h_{j}=+2$, some can feel $h_{j}=+1$, others

\footnotetext{
${ }^{6}$ If the scores of all the other activities do not change, it could mean that: 1) or the person did not include in his scores the hedonic inertia effect, because he evaluated in a very rational way his feeling only right connected to each specific action; 2) or there is no hedonic inertia effect. But, it is difficult to imagine the last case, which would mean that one wonderful activity in our day does not influence part of our mood.

${ }^{7}$ We call indifferently event or activity.

${ }^{8}$ Relative for them: that means, not doing the same activities, but feeling the same $h$, and same $h i$ results from activities of the day.

${ }^{9}$ Remembering what we mentioned in the previous paragraph, in this case the reply will probably be " $w$ " because we are asking how do you feel in this moment; for this we added as a condition: "with the same level of underground happiness $u$ and a similar type of day, that means a similar HI". In fact, without these conditions, the replies will not be accurate for the scope to deduce the Ponderation Curves.
} 
can feel $h_{j}=0$, because each one has different characters and different backgrounds. We already mentioned how $h$ ' can strongly be modified (becoming $h$ ), by $s c$ too.

Fig. 12 considers the case of the linear curve inside a family of Shape Curves of $h$ ', amplifying it (Amplification Curves of $h^{\prime}$ ).

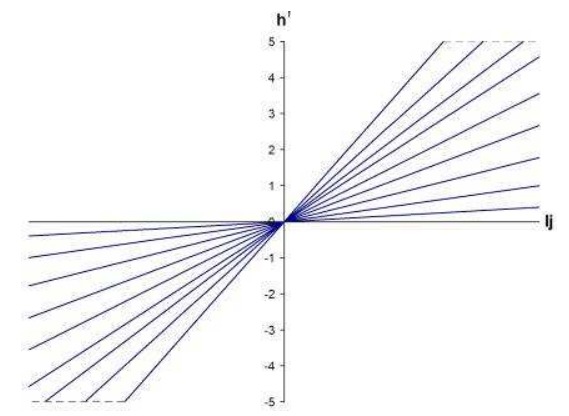

Fig. 12. Example of Ponderation Curves of $h$ ' for a certain $j$.

If $j$ is "working", "studying", and similar, $I j$ could be intended as "how deep the work/study is". If a person absolutely loves "working", "study", the deeper the work/study is, the more he probably will enjoy; if he likes $j$, the deeper it is, the more he will enjoy, but this time the relation will be less strong. If it is a linear relation, the straight line inclination will be lower. If a person does not like at all $j$, the relation will be negative.

We will have a family of curves for each type of event. For example the event "walking" will have a family of $z$ curves in which each curve characterizes a certain person (or - adding a stochastic factor - a certain typology of person). Idem for the event "sport", "reading a book", "working at the office", "going to a party", "sitting down on a bench", etcetera. Every person enjoys differently the same activity: for every curves' family of each event, a person is associated with a certain curve; or, that is the same, a person (or a personality typology), is associated with a certain set of $m$ curves, where each curve is one of the $z$ curves of one of the $m$ families of curves for the $m$ considered events.

Different personalities, cultures, characters, genetic predispositions, tempers, can read positive events and negative events in altered ways, giving same or different strength in influencing the good and bad experienced feelings $(h)$. This can be formalized by changing the symmetry of the function with respect to the origin of the axes.

Summarizing, firstly we have a kind of relation (Shape Curves), describing the relation among $I j$ and $h$ '. It can be linear, quadratic, cubic, etc. After that the inclination (if, e.g., we talk about a linear relation) of the straight line informs the importance that $j$ has for the person, and it is described by the Amplification Curve that change the angular coefficient of the straight line. By combining the Shape/Amplification Curves of $h$ ' and their symmetries, we obtain the Ponderation Curves of h' (different Profiles of h' Perception for different people).

In the same way, the underground happiness, $u$, connected with a same "stressful/joyful intensity" of a situation $(s), I s$, (love, career, health, money, politics, etc.), can be different for different people. As before, we will have families of curves for each situation considered: Shape Curves of $u$ and Amplification Curves of $u$, and we will obtain the Ponderation Curves of $u$ describing different Profiles of $u$ Perception.

The same reasoning can be suggested for the underground happiness from the scenario $(U s)$ in relation with the "intensity" (ISc) of different scenarios ( $s c)$ such as noise, urban quality, nature, aesthetics, etc. and obtaining the Ponderation Curves of Us describing specific Profiles of Us Perception. For example, if $s c$ is "aesthetics", the "intensity" (ISc) could be represented by picturing, e.g., the following images, and associating a symbolic value (e.g. from -3 to +3$)$, Fig. 13. Proportionally to the sensitivity to the factor "aesthetics", one can appreciate $(U s)$ the scenario on the right much more than another person. Geometrically talking, considering the case of linear relation, the sensitivity to the factor $u s$ is the angular coefficient of the straight line. 


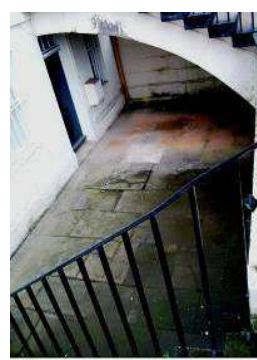

$-2$

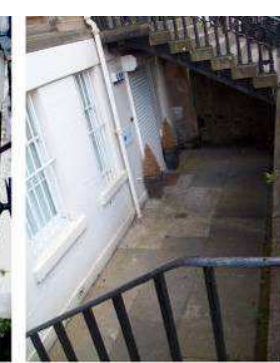

0

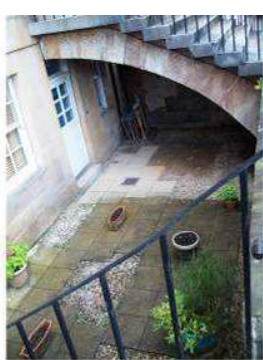

$+1$

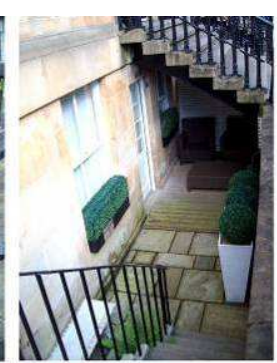

$+2$

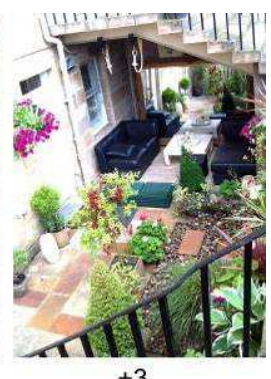

$+3$

Fig. 13. Example of different $I s c$

We do not mention any unit of measurement for the abscissas $I j$, Is, Isc because of the obscurity to objectively quantify them ${ }^{10}$. Also for the ordinate $u$ we cannot give a unit of measurement because we should at least know how much it can influence the global happiness ${ }^{11}$. Another observation is that some $j$ cannot have a $I j$ measuring its "intensity", but it can be just a point on the graph $h^{\prime} / I j$ rather than a curve; afterwards the point (like for the case of the curves), will be shifted more or less (ordinate axis), depending from several sc that can be associated to that $j$.

As we anticipated in the previous paragraphs, two different people experiencing a same $h_{j}$ level, can have different effects, related to $h_{j}$, during their global mood of the entire day $\left(h i_{j}\right)$. For example a depressive, negative, nature (or life period), could emphasize the negative experiences because of thinking more about them during the entire day (Fig. 14 on the right). On the contrary, a positive, joyful personality (or life period), could accentuate the positive experiences by keeping them in mind during the entire day more than the negative ones (Fig. 14 on the left). This can be formalized by choosing different values of the parameters $(n, \delta)$, for the positive events and the negative ones (graphically it means to alter the symmetry), having different Ponderation Curves of hi characterizing different Profile of hi Perception.

${ }^{10}$ The quantification of the charm of a specific sunset, or the beauty of a certain view, etc. in an objective scale, would be quite questionable. To quantify $I s$, for example of the factor "love", we can use as an objective scale, not numbers, but some standard state such as: being attracted, falling in love, marrying, some love problems with the partner, a big love problem with the partner, separation... Each person will have a different reaction $(u)$, in according to the importance (if linear relation, angular coefficient of the straight line $u / I S)$, that "love" has in his life. Idem, to give a scale of measurement of $I s$ for the factor "job", we can use: joblessness, having an unattractive job (unattractive for the person, or typology of person), having a neutral job, having a stimulating job... Idem for the factor "money", "health", etc. To quantify Isc for the factor "silence" we can use the noise level (this time then we are able to have a real objective, rational scale like the decibel); for the factor "aesthetics" we can compare a same set of appropriate images with different aesthetic levels, to find out the reaction $(U s)$ of different people. Etcetera for other factors we like to test. In the same way, to quantify $I j$ we can refer to a set of states rather than to numbers. For example, for $j=$ "doing a physical activity", we can present a set of states related with the physical effort-satisfaction level. For $j=$ "having breakfast", we can use some reference points as $I j$, such as: very small and fast breakfast, discrete breakfast, normal breakfast, satisfying breakfast, big breakfast. A person could feel $h^{\prime}=1$ for a small breakfast, another $h^{\prime}=0$ because maybe for him breakfast is a very important moment and meal. If we imagine the case of a linear relation, the inclination of the straight line will be proportional (angular coefficient) to the importance that that kind of factor/activity has for the person. For some $j$ the relation $I j$ and $h$ ' can be negative; e.g. the activity "doing a physical activity": if one loves it, the stronger the physical activity the higher he will enjoy. Vice-versa if one hates it. For some $j$ we cannot have any kind of measurement.

${ }^{11}$ For $h$, the maximum value is 5 , but can be another we prefer. For $h i$, it is realistic to believe that its maximum value could not be more than the maximum value of the $h$ with whom it is related $\left(h i_{j}<h_{j}\right)$. $U_{s}$ is automatically evaluated when the person judges $h_{j}$ for the specific activity $j$. However, if we want to build a simulated scenario for $a j$ activity ("working in an office"), rather than for a specific activity ("working at the office of Street... number..., $2^{\text {nd }}$ floor, room n.3, desk n.5"), Us will not be included in $h_{j}$, and we would need to know a value of $U s$ to add it to $h_{j}$ '. To do it we should at least be able to know how much $U_{s}$ can influence $h$ '; that means, how much more, or how much less, can shift the value of $h$ ' when you work in a specific office but changing (ceteris paribus), the quality of the view (facing a great window in front of a park, or facing a gray wall), the silence (being in a room facing a main traffic street, or a quiet court), etc. 

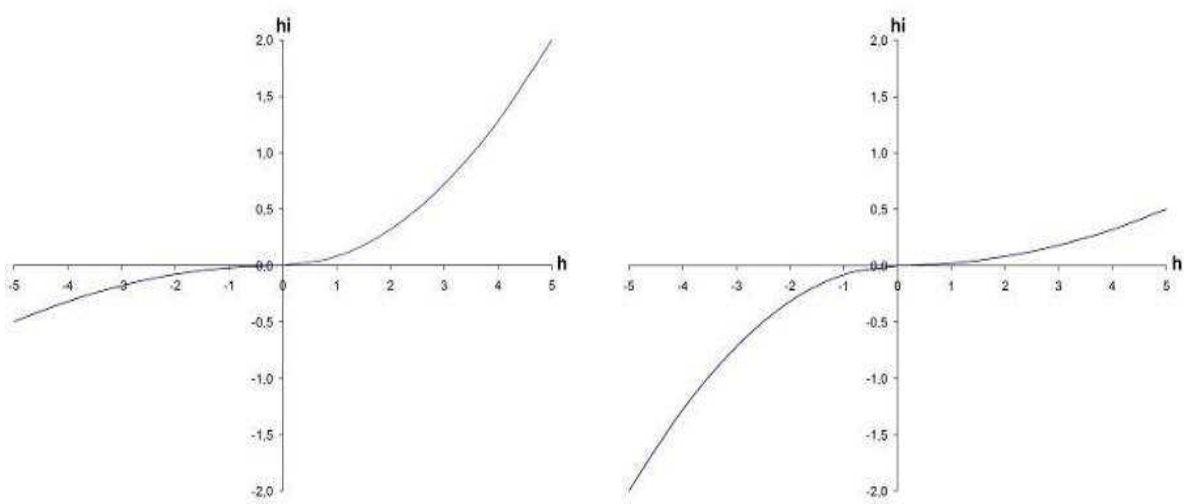

Fig. 14. Example of two Profiles of hi Perception described by two specific Ponderation Curves of hi.

By combining different values, and asymmetry, of the parameters $n, \delta$, and of $f\left(t_{j}\right)$, we can build diverse specific profiles of person that we called: Profiles of hi Perception.

Finally, the Profile of Hedonic Response of a person (or of a personality typology), is given by the combinations of all the previous steps calculated for a certain number $n$ of $s c$, a certain number $m$ of $j$, a certain number $r$ of $s$ and by the Profile of hi Perception.

Summarizing:

- $\quad$ by combining the Shape Curves of $h i$ with the Amplification Curves of $h i$ and, different symmetries, we obtained the Ponderation Curves of hi, where a single curve describes a certain Profile of hi Perception;

- $\quad$ for each $s c, j$ and $s$ we obtained a certain Profile of h'Perception, a Profile of $u$ Perception, and a Profile of Us Perception;

- the Profile of hi Perception and the set of the Perception Profiles for a certain number $n$ of $s c$, a certain number $m$ of $j$ and a certain number $r$ of $s$ we like to investigate, provide the Profile of Hedonic Response.

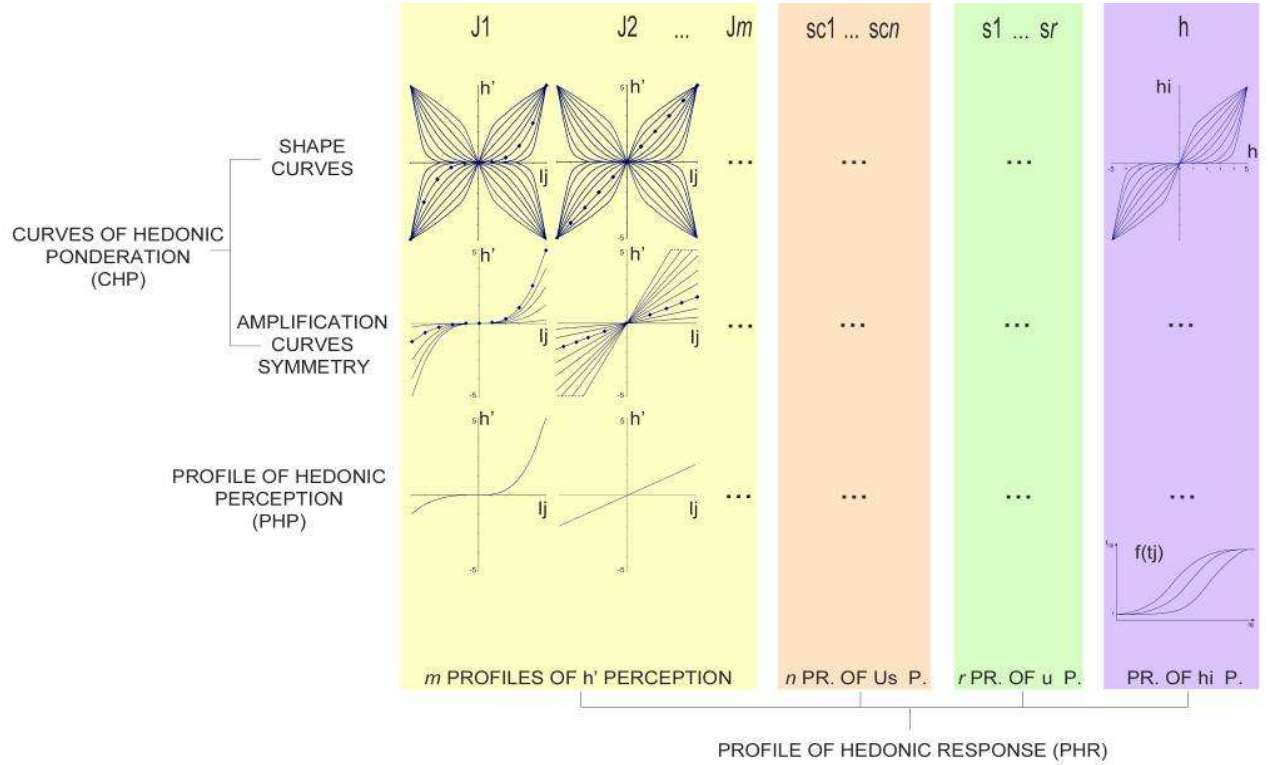

Fig. 15. Synthesis of the Underground Hedonic Theory

We generically call Curves of Hedonic Ponderation (CHP), the ponderation curves of $h$ ', $h i, u$ and $U s$; and we call Profiles of Hedonic Perception (PHP) the profiles of perception of $h$ ', hi, $u$ and Us. The Profile of Hedonic Response (PHR), of a person (or of a personality typology, adding a stochastic variable), is a specific set of PHP, given by a specific combination of CHP. 
Apart from the PHR related to the relation $h i / h$, each PHR is associated with a specific $j, s c$, and $s$. The more types of $j, s c$ and $s$ we will investigate for a certain person (or personality typology), the more PHR describing the person's replies we will have.

Fig. 15 is an overall synthesis of the Underground Hedonic Theory proposed in this paper. Rather than a Theory, it is, much less ambitiously, a reminder of some of the steps that usually are on the basis of the daily mood formation.

Independently from the numerous different ways to perceive feeling among different people, and between different life periods of a same person, the mechanism on the basis of the formation of the global feeling of happiness that we are trying to formalize, can elementarily be summarized by the following steps: each activity $(j)$ of the day gives a certain level, $h$, of happiness/mood, (Fig. 16 and Fig. 17a), and has an $h i$ effect (negative or positive) spread throughout the day (Fig. 17b); the underground happiness from the scenario (Us), influences part of $h$; the $h i$ of each activity shift, up or down, (Fig. 17c) the global mood of the entire day; idem for $u$, shifts, up or down, the global feeling of happiness during the day (Fig. 17d).

The next Fig. 16 shows an example of these steps for a certain day of a person.

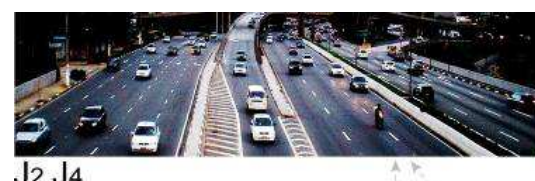

$\mathrm{J}_{2,} \mathrm{~J}_{4}$

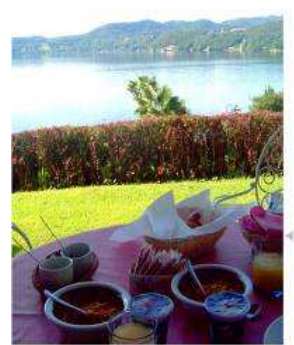

$\mathrm{J}_{1}$

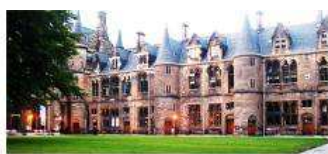

$\mathrm{J}_{3}$

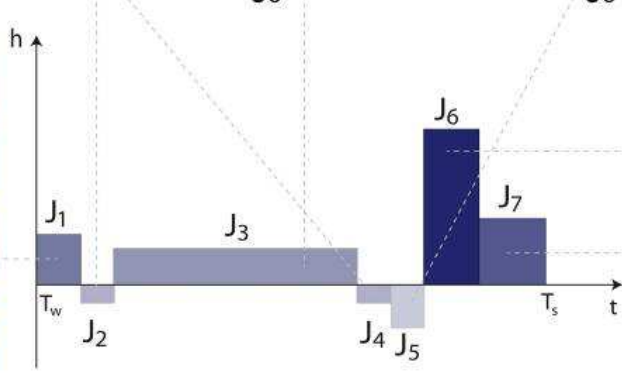

Fig. 16. Example of a day of a certain person

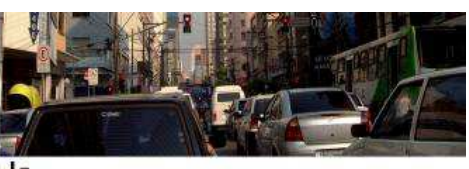

$\mathrm{J}_{5}$

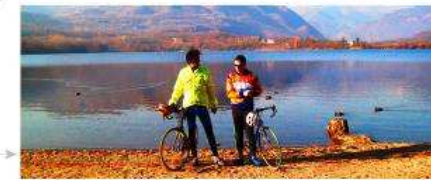

J6

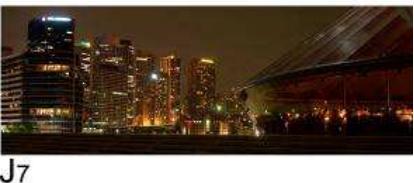

$\mathrm{J} 7$

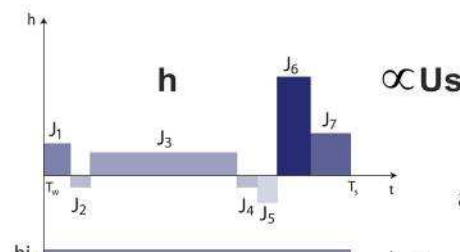

a)
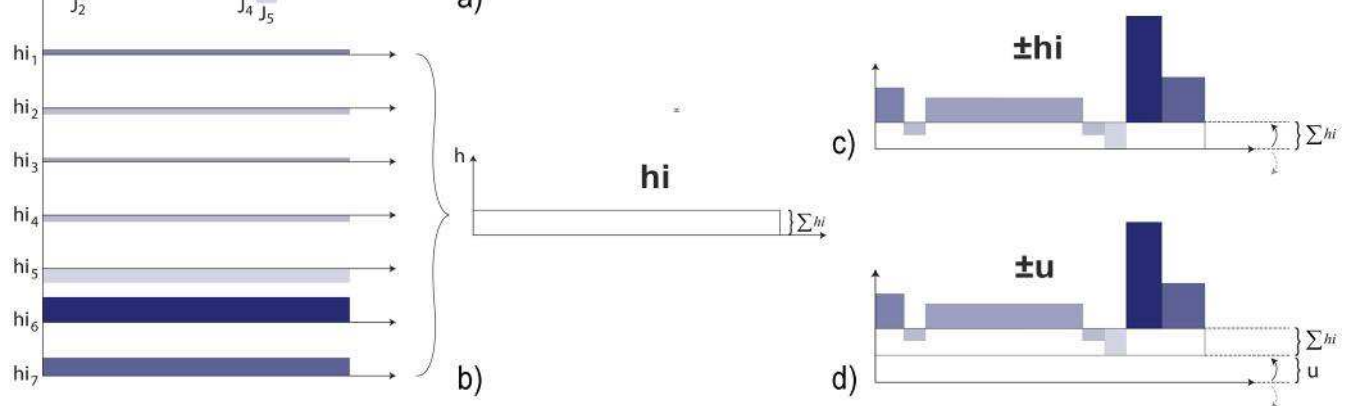

Fig. 17. Steps of analysis

When the aim is building a virtual scenario, we ask questions like "how much quietness, aesthetics, silence, ..., are important to you?" (to estimate Us); "how do you usually feel when you have a run?" $(h$ '), "how much love, career, money, health... are important in your life?" $(u)$. Looking at Fig. 17, to estimate the global happiness, we sum a), c) and d) ${ }^{12}$.

\footnotetext{
12 In this case, to be punctilious, we should include the consideration that one can usually love " 3 " reading a book, but can love " 3.5 " if he does it after dinner, " 2.5 " if before. However, in most cases, we could be able to include this kind of "shrewdness" thanks to $U s$, by investigating the right range of $s c$.
} 
When we ask questions like "how do you usually feel when you run $(h$ ') in the park in front of your house with your friend (Us)?", the reply $\left(h=h^{\prime}+U_{s}\right)$, will include $U_{s}$, but not the others $h i(\mathrm{c}))$, and not $u(\mathrm{~d}))$.

When we ask, during each moment of the day, questions like "how are you feeling right now?" (by following the example of the previous question: "how did you feel today when you ran?"), to estimate the global ${ }^{13}$ happiness, the information we need are already all in point a), because the reply ( $w)$, should already include c) and d) too.

\section{Public policies and underground happiness}

At the end of this brief argumentation around the ideas of hedonic inertia and underground happiness, we like to remark on the part public policies can play in all this.

The factor that can be altered by public policies and by social behaviour, is the variable "sc" giving the underground happiness from the scenario (Us), and part of $u$ too.

For example, urban plans can deeply improve our $U s$ thanks to nice parks, quality of squares, buildings, pedestrian areas, etcetera, as well as thanks to policies improving the quality, the efficiency and the comfort of public transport ${ }^{14}$. If we study (Fig. 18), work (Fig. 19), pass through (Fig. 20), spent our free time (Fig. 21), etc., in a nice underground environment, such as a pleasant city area, well designed and beautiful buildings, no traffic, noise and pollution, pedestrian areas, parks and gardens, etc., our Us can be sensibly improved.
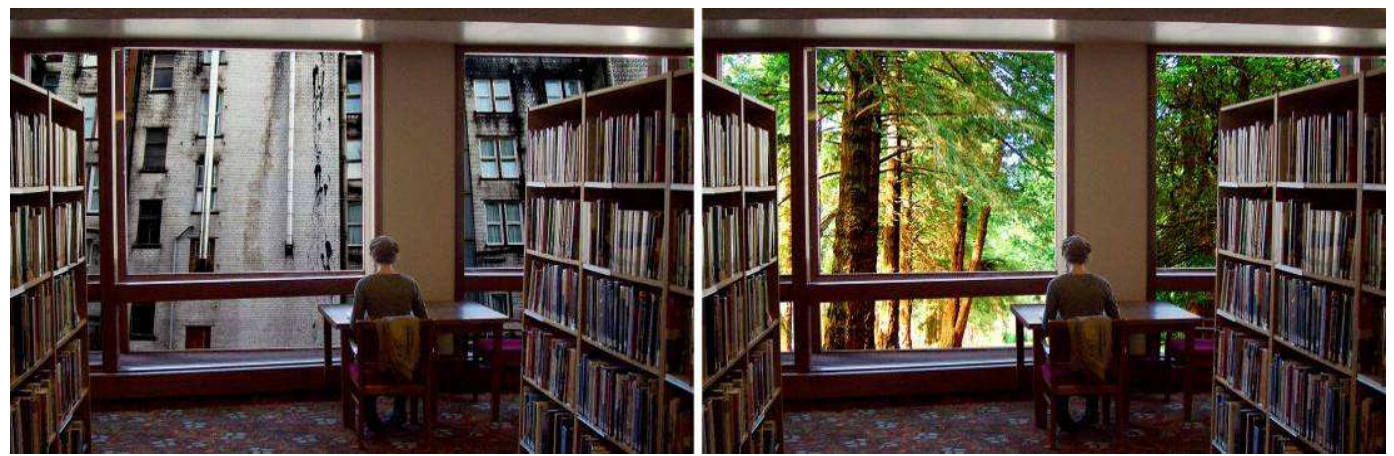

Fig. 18
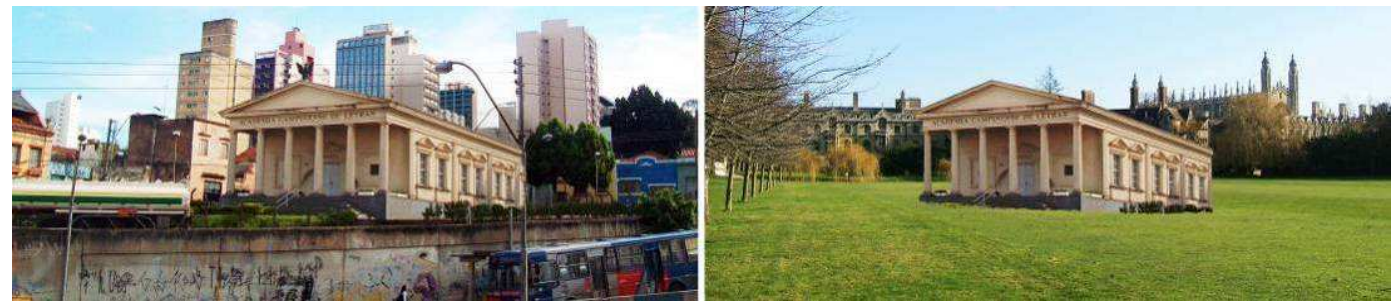

Fig. 19

\footnotetext{
${ }^{13}$ As we noticed in a previous note, in this case $(w)$, if there is an unexpected nice or bad event, the sum of $w$ along the day will not be able to give a global psychological sum of the happiness, but will provide an algebraic sum. This because the $h i$ effect of that unexpected event cannot be spread along the antecedent period. In this case the algebraic sum informs about the total sum of the happiness felt during each moment of the day. However the global feeling of the entire day, (as a post-evaluation), could amplify a single event independently from when it happened during the day (in the morning, in the afternoon, at night). This amplification in order to give the global phsycological sum, is numerically allowed (even if just symbolically, because without any empirical support), by spreading the $h i$ along the entire day, and not just after the time it happened.

${ }^{14}$ D'Acci (2013a, 2009).
} 

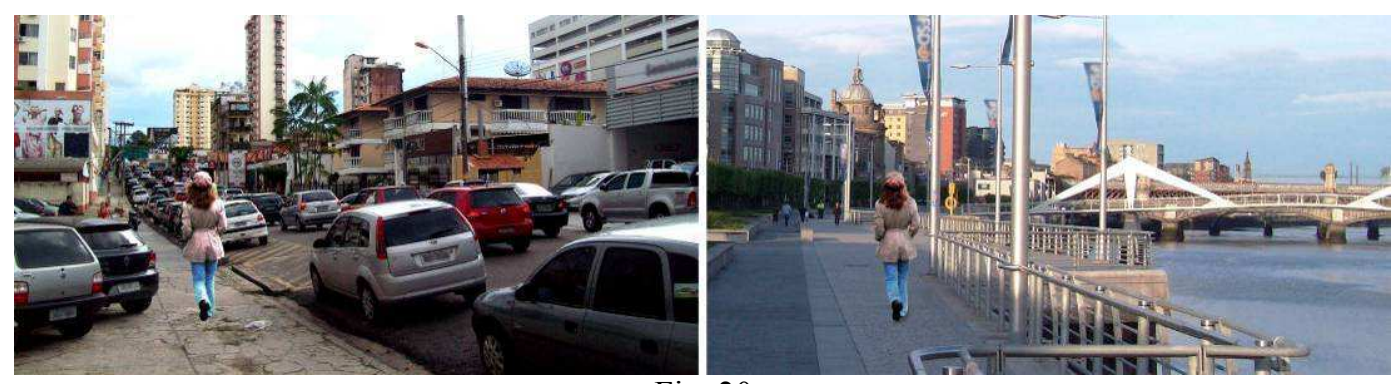

Fig. 20
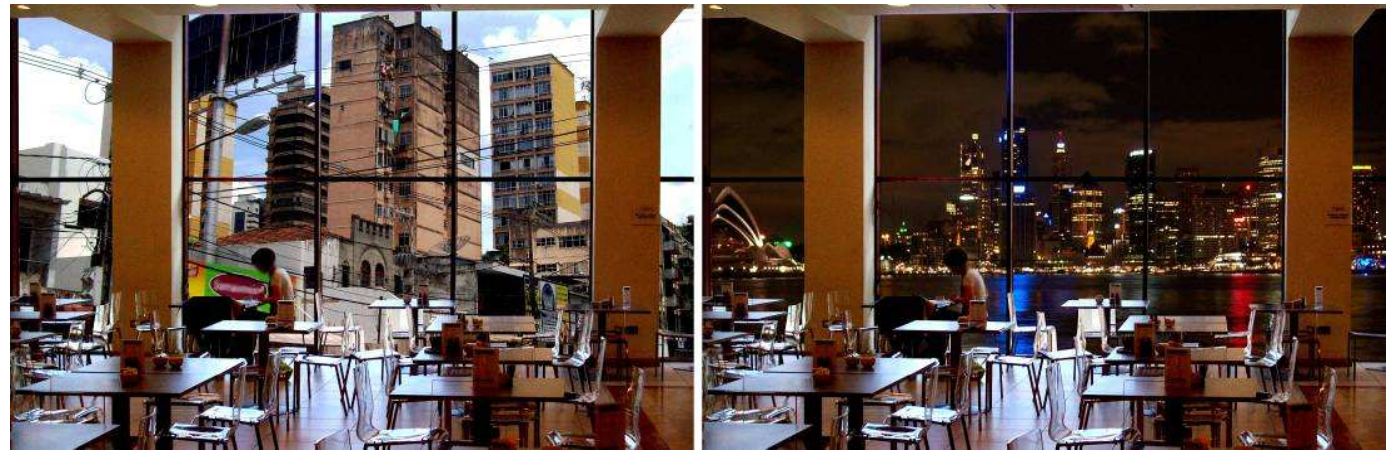

Fig. 21

Improving $U_{S}$ it means improving $h$; improving $h$ means improving $h i$; and also, "being conscious" to live in a nice city, improves a part of $u$ too. In fact, being aware ${ }^{15}$ of living/working in an agreeable area/city is comparable to a situation $(s)$ such as "love", "job", "money", "health", "political/economic country situation", etc., previously mentioned when talking about the underground happiness $(u)$. If one is jobless, or with health problems, or love problems, etc., $(s)$, his $u$ level will be reduced, and will shift down all the happiness levels felt during the activities of the day. Idem if one is aware of living in an unpleasant city or area.

These kind of factors can play a double role: one inside the formation of $h$ (by $U s$ ), and one inside the formation of $u$. Looking at it in another way, we also think how $h$ produce $h i$, and we can understand how some $h i$ related to "permanent" or "enduring" event/activities play a role in the formation of $u$ too: such as working at that permanent/enduring office; having that permanent/enduring job; living permanently/enduringly in that home; living permanently/enduringly in that city, and so forth. Therefore we can notice that there is an interrelation among $h, U s, h i$ and $u$.

\section{Some further consideration}

As we discerned, the Ponderation Curves of $h$ ', hi and $U_{s}$, that provide specific profiles, depend in part from $u$, and from a certain range of various underground situation natures.

For example, (D'Acci 2013b, 2010), the happiness we feel buying a bike, is proportional to questions such as: "is it my first bike?', "'how important is it for my own philosophy of life to have a bike, or to have a beautiful bike?", "how useful is it for me to have this kind of physical activity?", "how fulfilling is it to move/travel in an ecological way?', 'how does my new bike compare with my previous one, and with the bikes of people around me?', etc.. There is an enormous literature and an historic dispute covering this subject. We refer for example to Sen (1987) for a discussion about rationality, utility and ethics; Kahneman (1994, 2003) about a connection among utility, rationality and surrounding situation; some research illustrated in Frey and Stutzer (2002) showing how happiness is dependent on the surrounding situation.

The aim of this paper does not directly embrace the process of $h$ formation; however we briefly show some examples (D’Acci 2013b, 2010), of known theories in the literature.

\footnotetext{
${ }^{15}$ We remind how, in general, for every "s", the fact of "being aware", is crucial in the evaluation of $u$. For example one could not adequately appreciate the situation to be healthy until some serious health problem will happen to him, or to a person close to him. Idem for the money situation, the political-economic national situation, and so forth.
} 
The Independence from the reference ("how rich I am at this moment") is the base of the Theory of expected utility of Bernoulli, where the (rational) decider makes choices for the expected utility of future situations. In this theory, the preferences of the decider remain identical, because the utility does not depend on the present situation. This Bernoulli's theory is on the basis for the modern Theory of Decisions, that conserved the assumption of independence from the reference (so called by Tversky and Kahneman 1991) in its future versions.

The Adaptation-level theory ${ }^{16}$ (after a certain time, an improvement of our condition does not produce an increase of happiness), and the Aspiration level theory ${ }^{17}$ (my happiness depends on the distance between "how much I wish for" and "how much I have") are historically well known too.

The effect of "shifting of preference toward the high" (the more I have the more I want) can delete part of the objective well-being.

A different version of the Adaptation-level theory is the idea of the homeostatic process: even after several modifications in your life condition, your happiness tends to go back to your original level of happiness. It is like your happiness derives more from your genetic predisposition rather than from events changing your life (Headey \& Wearing 1992).

The Procedural Utility ${ }^{18}$ concept is connected to the happiness we can receive through the process by which we reach a goal (material or immaterial goal).

Our feeling of "happiness" also depends on the level of well-being of people around us: how much richer or poorer they are in comparison to $\mathrm{me}^{19}$, or how much happier/unhappier they are compared to me, etc.

We also cite other models that can suggest several approaches and opinions for understanding some parts of the "happiness process", such as the Opponent-process theory of motivation $^{20}$, the Hedonic contingency theory ${ }^{21}$, the Hedonic treadmill model (good and bad events provisionally affect happiness, but after a certain time period, people can adapt back to a hedonic neutrality) ${ }^{22}$, the Mood-behaviour model ${ }^{23}$, the Discrete emotion theory ${ }^{24}$, the Selfcenteredness and selflessness theories ${ }^{25}$, the Theory of positive psychology ${ }^{26}$ the SelfDiscrepancy/Self-regulation Theory ${ }^{27}$, Construal level theory approach ${ }^{28}$, the Hedonic Tone Theory ${ }^{29}$ and so forth.

\section{Conclusion}

Both concepts of Hedonic Inertia and Underground happiness require empirical and theoretical development to be usefully applied. Some extensive survey work to understand how a period of elevated or diminished experience utility matters for a momentary assessment of happiness and of the hedonic inertia effect is required too. Theoretically it is to be expected to improve the functional form of the equation, as well as empirically it is essential to find the right output to be able to discuss the best mathematical form of the equation and to give the most suitable values for the parameters. The equations presented in this paper could be used as numerical support for different theories of reference, where each theory will suggest a particular value for each parameter, a specific (or a range) Shape Curve, Amplification Curve,

\footnotetext{
${ }^{16}$ Helson (1964), Brickman and Campbell (1971), Parducci (1995), Frederick and Loewenstein (1999).

${ }^{17}$ Irwin (1944), Michalos (1991), Inglearth (1990).

${ }^{18}$ Frey \& Stutzer (2002), Frey et al. (2002), Hanh (1984). The literature suggests to call Procedural Utility the satisfaction given by the process of reaching the goal, and calling the instrumental utility that one received when we reach the intended goal. Then the psychological well-being concerns both the final state and the procedure.

19 Easterling (1974), Easterlin (1995), Veblen (1899), Becker (1974), Frank (1985), Pollak (1976), Duesenberry (1949), Russel (1930) p. 68-69, Kosicki (1987), Hirsch (1976).

${ }^{20}$ Solomon R. L. \& Corbit J. D. (1974).

${ }^{21}$ Hirt E.R., Devers E.E. \& McCrea S.M. (2008).

${ }^{22}$ Diener E., Lucas R. E. \& Scollon C. N. (2006).

${ }^{23}$ Gendolla G. H. E. (2000).

${ }^{24}$ Lench H. C., Flores S. A. \& Bench S. W., (2011).

${ }^{25}$ Dambrun M. \& Ricard M., (2011).

${ }^{26}$ Kristjánsson K., (2010).

${ }^{27}$ Higgins E.T. (1987).

${ }^{28}$ Lyubomirsky S., (2001).

${ }^{29}$ Johnston (1999).
} 
$f\left(t_{j}\right)$, a certain symmetry/asymmetry of the function with respect to the origin of the axes, etc. All this only if we still expect that a maths function is capable of explaining happiness.

In fact, apart from the technical considerations shown in this superficial paper, any temptation to define, and, even worst, to force complex, fuzzy and polyhedric concepts as happiness into an equation reducing it into a final number, is as challenging as vain.

This paper does not have any psychological aims/background; it just summarized the role that hedonic inertia $(h i)$, underground happiness $(u)$, and scenario $(U s)$, play on the formation of daily happiness.

Literature and common sense, suggest that happiness, subjective wellbeing, experienced happiness, mood, satisfaction, experienced utility, or in which ever way we prefer to call it, is connected - ceteris paribus - to gender, education, age, culture, nation, past memories, DNA, and so forth. Different personalities, characters, past personal histories, genetic predispositions, etc., can read positive events and negative events in altered ways, giving same or different strengths in influencing the experienced utilities. Again, some people can have a more platonic, romantic, sensitive, dreamer temper and, therefore, give more importance to the $h i$, and some $u$ and $U s$ effect during their daily life, apart from feeling different $h$ levels for the same kind of event. On the contrary, a person with a more dispassionate, cold, frigid, nature can be less susceptible to the $h i$ and $u$ effect during his activities of his daily life.

Independently from this variability in the perception of happiness, showing the importance of hedonic inertia and underground happiness concepts, could offer a point of view and reflection for some public policy decisions influencing the daily life of people. For example, public goods, such as nice parks, pedestrian streets and squares, general urban quality, design, comfortable transport system, etc., can provide several underground happiness effects that can improve the average quality of life of citizens, and not just during the time they are using them.

The reader could find some kind of logic contradictions in the concepts and mechanisms shown; for this we like to repeat and underline the limits and the shallowness of them, as well as the incapacity of an equation and of a comprehensive reasoning, to manage the tremendous number of variables required for the evaluation of such a complex enigma as happiness.

\section{References}

Allport, G. (1937). Personality: A psychological intrepretation. New York, NY: H. Holt and Co.

Allport, G. (1935). Attitudes. In C. Murchison (Ed.), A handbookd of social psychology (pp. 798844). Worcester, MA: Clark University Press.

Angner, E. (2011). "The evolution of eupathics: the historical roots of subjective measures of wellbeing". International Journal of Wellbeing, 1(1), 4-41.

Bentham, J. (1789). An Introduction to the principles of morals and legislation. Reprinted in (2007): Mineola, NY: Dover publications.

Campbell, A. (1976). Subjective measures of well-being. American Psychologist, 31(2), 117-124.

D'Acci L. (2013a), "Urban quality of life estimates", Encyclopedia of Quality of Life Research, Springer.

D'Acci L. (2013b), "Wellbeing and progress measurement", Encyclopedia of Quality of Life Research, Springer.

D'Acci L. (2012), "The Positional Value. Influence of the city area quality on the real estate value", (submitted).

D'Acci L. (2010), "Measuring Well-Being and Progress", Social Indicators Research, Vol 104, Issue 1, Pages 47-65.

D'Acci L. (2009), "Spatial Distribution of Social Benefit Given by Urban Attractions: a Test of UrAD Model", in Lecture Notes in Computer Science LNCS 5592, pp. 237-252, Springer-Verlag, Heidelberg.

Dambrun M. \& Ricard M., (2011), "Self-centeredness and selflessness: A theory of self-based psychological functioning and its consequences for happiness", Review of General Psychology, Vol 15(2), 138-157.

Davis, K. B. (1929). Factors in the sex life of twenty-two hundred women. New York, NY: Harper \& Brothers.

Diener E., Lucas R. E. \& Scollon C. N. (2006), "Beyond the hedonic treadmill: Revising the adaptation theory of well-being", American Psychologist, Vol 61(4), 305-314. 
Diener E., Pavot W. (1993), "The Affective and Cognitive Context of Self-Reported Measures of Subjective Well-Being”, Social Indicators Researche 28(1), 1-20.

Johnston V.S. (1999), "Why We Feel: The Science of Human Emotions”, Perseus Press: Reading, Mass.

Juster F.T., Courant P.N., Dow G.K. (1985), “A Conceptual Framework for the Analysis of Time Allocation Data", in Time, Goods, and Well-Being, Juster F.T., Stafford F.P., eds. Arbor A., Mich.: Institute for Social Research, University of Michigan, pp. 113-131.

Kahneman , D. (2010). in Jarden, A. An interview with Daniel Kahneman, International Journal of Wellbeing, 1(1), 186-188.

Kahneman D. (2006), "Developments in the measurement of subjective well-being", The Journal of Economic Perspectives, 20, 3-24.

Kahneman D. (2004), "Toward National Well-Being Accounts", The American Economic Review, 94, 2, pp. 429-434.

Kahneman D., Krueger A.B., Schkade D.A., Scharw N., Stone A. (2004a), A survey method for characterizing daily life experience: The Day Reconstruction Method (DRM), Science 306:5702, pp. 1776-1780.

Kahneman D., Diener E., Shkade N., Stone A. (2003), A survey method for characterizing daily life experience: The Day Reconstruction Method (DRM), Mimeo, Princeton University, Princeton (N.J.).

Kahneman D. (1994), "New Challenges to the Rationality Assumption", Journal of Institutional and Theoretical Economics, 150, 1, pp.18-36.

Easterlin R. (1995), “Will Raising the Incomes of All Increase the Happiness of All?”, Journal of Economic Behaviour and Organization, 27(1), pp. 35-48.

Easterling R. (1974), "Does Economic Growth Improve the Human Lot? Some Empirical Evidence", in David P.A., Reder M.W. (eds), Nations and Households in Economic Growth: Essay in Honor of Moses Abroamowitz, Academic Press, New York, pp. 89125.

Edgeworth, F.Y. (1881). Mathematical Psychics: An Essay on the Application of Mathematics to the Moral Sciences. Reprinted in (2003): Mathematical Psychics and Futher papers on Political Economy. New York, NY: Oxford University Press.

Frank R. (1985), “The Demand for Unobservable and Other Non-positional Goods", American Economic Review, 75(1), pp. 101-116.

Frey B.S., Benz M., Stutzer A. (2002), Introduction to Procedural Utility: Not only What, but also How Matters, Institute for Empirical Research in Economics, University of Zurich, Working Papers Series, n. 129, forthcoming in Journal of Institutional and Theoretical Economics.

Frey B.S., Stutzer A. (2002), Happiness and Economics, Princeton University Press, Princeton, [it. tr. (2006), Economia e felicità, Il Sole24ore, Milano].

Frederick S., Loewenstein G. (1999), "Hedonic Adaptation", in Kahneman D., Diener E., Scwarz N. (eds), Well-Being: The Foundations of Hedonic Psychology, Russel Sage Foudantions, New York, pp. 302-329.

Gendolla G. H. E. (2000), "On the impact of mood on behavior: An integrative theory and a review", Review of General Psychology, Vol 4(4), 378-408.

Goldings, H. J. (1954). "On the avowal and projection of happiness", Journal of Personality, 23(1), $30-47$.

Gurin, G., Veroff, J., \& Feld, S. (1960). Americans view their mental health: A nationwide interview survey. New York, NY: Basic Books.

Hart, H. (1940). Chart for happiness. New York, NY: Macmillan.

Headey, B. \& Wearing, A. (1992). Understanding happiness : a theory of subjective wellbeing. Melbourne: Longman Cheshire.

Helson H. (1964), Adaptation-Level Theory: An Experimental and Systematic Approach to Behaviour, Harper \& Row, New York.

Higgins E.T. (1987), "Self-discrepancy; A theory relating self and affect", Psychological Review, 94, 319-340.

Hirt E.R., Devers E.E. \& McCrea S.M. (2008), "I want to be creative: Exploring the role of hedonic contingency theory in the positive mood-cognitive flexibility link", Journal of Personality and Social Psychology, Vol 94(2), 214-230.

Inglearth, R. F. (1990), Culture shift in advanced industrial society. Princeton, NJ: Princeton University Press. 
Irwin F.W. (1944), “The Realism of Expectations”, Psychological Review, n.51, pp. 120-126.

Lench H. C., Flores S. A. \& Bench S. W., (2011), "Discrete emotions predict changes in cognition, judgment, experience, behavior, and physiology: A meta-analysis of experimental emotion elicitations", Psychological Bulletin, Vol 137(5), 834-855.

Leu R.E., Burri S., Priester T. (1997), Lebensqualitat und Armut in der Schweiz, Haupt, Bern.

Lyubomirsky S., (2001), "Why are some people happier than others? The role of cognitive and motivational processes in well-being", American Psychologist, Vol 56(3), 239-249.

Marshall A. (1890), Principles of Economics, $8^{\text {th }}$ ed. (1920), Macmillan, London.

Murray, H. A. (1938). Explorations in personality: A clinical and experimental study of fifty men of college age. New York, NY: Oxford University Press.

Neugarten, B. L., Havighurst, R. J., \& Tobin, S. S. (1961). The measurement of life satisfaction. Journal of Gerontology, 16(2), $134-143$.

Sen A. (1987), On Ethics and Economics, Basil Blackwell, Oxford.

Solomon R. L. \& Corbit J. D. (1974), “An opponent-process theory of motivation: I. Temporal dynamics of affect", Psychological Review, Vol 81(2), 119-145.

Tversky A., Kahneman D. (1991), "Loss Aversion in Risksless Choice: A Reference-Dependent Model”, Quarterly Journal of Economics, 106(4), pp- 1039-1061.

Watson G. (1930). Happiness among adult students of education. Journal of Educational Psychology, 21(2), 79-109.

Veblen T. (1899), The Theory of Leisure Class, Modern Library, New York. 